\title{
A NUMERICAL STUDY ON THE EFFECT OF BEACH NOURISHMENT ON WAVE OVERTOPPING IN SHALLOW FORESHORES
}

\author{
Tomohiro Suzuki ${ }^{1,2,3}$, Toon Verwaest ${ }^{1}$, William Veale ${ }^{1,2}$, Koen Trouw $^{4,5}$ and Marcel Zijlema ${ }^{3}$ \\ In this paper, the effect of beach nourishment on wave overtopping in shallow foreshores is investigated with the non- \\ hydrostatic wave-flow model SWASH. Firstly, the applicability of SWASH to model wave overtopping is tested by \\ comparing results with a physical model setup with different storm wall heights on top of an impermeable sea dike. \\ The numerical results show good agreement with the physical model. After validation, sensitivity analysis of the \\ effect of beach nourishment on wave overtopping is conducted by changing bottom configurations with the SWASH \\ model. From the sensitivity analysis, it becomes clear that wave overtopping discharge in shallow foreshores is \\ characterized by the bores generated in surf zone due to wave breaking. To reduce wave overtopping discharge in \\ shallow foreshore, it is important to reduce the horizontal momentum of the bores.
}

Keywords: SWASH model; beach nourishment; wave overtopping; infragravity waves; bores; shallow foreshores

\section{INTRODUCTION}

The potential for sea level rise and increased storm intensity in the coming decades are great threats for those areas located in low lying coastal regions such as the Flemish coast. Existing coastal defenses are often insufficient to protect against extreme storms, and it is therefore urgent to design protective countermeasures. In Belgium, the Integrated Coastal Safety Plan (Afdeling Kust, 2011) has been approved by the Flemish government to realize protection against extreme storm events. It indicates the criteria for wave overtopping discharge $1 \mathrm{l} / \mathrm{s} / \mathrm{m}$ for ' 1000 year storm' and $100 \mathrm{l} / \mathrm{s} / \mathrm{m}$ for ' $+8 \mathrm{~m}$ TAW super storm'. It is noted that the return period of the ' $+8 \mathrm{~m}$ TAW super storm' is estimated 17,000 years (Verwaest et al., 2009). The present coastal defenses do not satisfy these criteria at all locations on the Flemish coast.

The master plan recommends using a combination of beach nourishment and storm walls to provide protection against wave overtopping. However, the relationship between beach nourishment and wave overtopping discharge in shallow foreshores is not very clear due to the limitation of the applications and the complexity of wave breaking on the shallow foreshore (e.g. Van Gent, 1999, 2001; Van Gent and Giarrusso, 2003) existing in the Flemish coast.

Traditionally, wave overtopping discharge is calculated by estimating wave boundary conditions at the toe of a coastal structure, and then applying empirical wave overtopping formulas such as EurOtop (2007). Wave boundary conditions are typically estimated using physical models and numerical models. Physical models give reliable estimations of wave boundary conditions, however, they require the expense of considerable time and cost. Also changes in physical model topography is not always straightforward, thus numerical models have often been used in recent times. However, numerical models do not always represent wave transformation processes accurately on shallow foreshores. In these areas, long waves triggered by wave breaking and wave-wave interaction play an important role on wave transformation. Thus it is important to choose a model which is capable to reproduce reasonable wave breaking process and nonlinear wave-wave interactions for the accurate estimation of wave overtopping.

Many numerical studies have been done in terms of surf zone hydrodynamics such as wave breaking and wave-wave interaction. Reynolds Averaged Navier-Stokes models (e.g. Lara et al., 2008; Troch et al. 2002) are certainly one of the best options to reproduce these processes, however, it still needs a lot of computational resources. It is often the case that the model needs to calculate a twodimensional horizontal domain with a relatively long duration (e.g. 1000 waves), so efficient computation is desirable. Recently a phase-resolving wave propagation model, SWASH (Zijlema et al., 2011), based on the non-linear shallow water equations with a non-hydrostatic pressure model has been developed. With this model, efficient computation of waves can be possible. Suzuki et al. (2011) has

\footnotetext{
${ }_{1}^{1}$ Flanders Hydraulics Research, Berchemlei 115, B-2140 Antwerp, Belgium, tomohiro.suzuki@mow.vlaanderen.be

2 Dept. of Civil Engineering, Ghent University, Technologiepark 904, B-9052 Ghent, Belgium

${ }^{3}$ Environmental Fluid Mechanics Section, Faculty of Civil Engineering and Geosciences, Delft University of

Technology, P.O. Box, 2600 GA Delft, The Netherlands. M.Zijlema@tudelft.nl

${ }_{5}^{4}$ Flemish Agency for Maritime Services and Coast, Vrijhavenstraat 3, B-8400 Oostende, Belgium

${ }^{5}$ Fides Engineering, Sint Laureisstraat 69d, B-2018 Antwerp, Belgium, Koen.Trouw@fidesengineering.be
} 
already demonstrated that this model produces satisfactory results for both wave transformation and wave overtopping for shallow foreshore topography.

The objective of this study is to extend the work of Suzuki et al. (2011) and apply it to investigate the effect of beach nourishment. In this study, the model validations for wave overtopping and a sensitivity analysis to beach nourishment are presented.

\section{NUMERICAL MODEL}

The SWASH model is a time domain model for simulating non-hydrostatic, free-surface and rotational flow. The governing equations are the shallow water equations including a non-hydrostatic pressure term. The one-dimensional, depth-averaged shallow water equations in non-conservative form are shown as follows:

$$
\begin{gathered}
\frac{\partial \zeta}{\partial t}+\frac{\partial h u}{\partial x}=0 \\
\frac{\partial u}{\partial t}+u \frac{\partial u}{\partial x}+g \frac{\partial \zeta}{\partial x}+\frac{1}{2} \frac{\partial q_{b}}{\partial x}+\frac{1}{2} \frac{q_{b}}{h} \frac{\partial(\zeta-d)}{\partial x}+c_{f} \frac{u|u|}{h}=\frac{1}{h} \frac{\partial}{\partial x}\left(h v_{t} \frac{\partial u}{\partial x}\right) \\
\frac{\partial w_{s}}{\partial t}=\frac{2 q_{b}}{h}-\frac{\partial w_{b}}{\partial t} \\
w_{b}=-u \frac{\partial d}{\partial x} \\
\frac{\partial u}{\partial x}+\frac{w_{s}-w_{b}}{h}=0
\end{gathered}
$$

where $t$ is time, $x$ the horizontal coordinate, $u$ the depth averaged velocity in $x$-direction, $w_{s}$ and $w_{b}$ the velocity in $z$-direction at the surface and at the bottom, respectively. $\zeta$ is the free-surface elevation from still water level, $d$ is the still water depth and $h$ the total depth. $q_{b}$ is the non-hydrostatic pressure at the bottom, $g$ the gravitational acceleration, $c_{f}$ the dimensionless bottom friction coefficient and $v_{t}$ the eddy viscosity.

A full description of the numerical model, boundary conditions, numerical scheme and applications are given in Zijlema et al. (2011).

\section{VALIDATION}

\section{Physical model set-up}

Physical model tests for wave transformation and wave overtopping have been conducted in the large wave flume at Flanders Hydraulics Research, Belgium (Veale et al., 2011). The wave flume measured $70 \mathrm{~m}$ long, $4.0 \mathrm{~m}$ wide and $1.4 \mathrm{~m}$ high. The wave flume was divided by 4 cross-sections and the width of the each cross-section was $1.0 \mathrm{~m}$. The overtopping measurement was conducted by the two cross-sections and the other two was used as passive wave absorption system. A piston type wave generator with a stroke of $0.6 \mathrm{~m}$ was used for the wave generation. It is noted that the wave generator does not have active wave absorption system.

The model bathymetry, sea dike and storm wall were constructed at a scale of 1:25 as shown in Figure 1. The vertical axis of the figure shows prototype scale while the horizontal axis is in model scale. The level of the offshore bottom, the toe of the dike and the dike crest were set as $-16.68 \mathrm{~m}$, $+6.50 \mathrm{~m}$ and $+8.38 \mathrm{~m}$ TAW (Tweede Algemene Waterpassing; Belgian standard datum level, corresponding closely to MLLWS) in the prototype scale, respectively. The topography was simplified into a $1 / 35$ slope starting $13.3 \mathrm{~m}$ from the wave paddle up to the toe of the dike, and constructed from smooth concrete. The dike has a wide crest with a seaward 1/100 slope and the level at the end of the dike is $+8.56 \mathrm{~m}$ TAW. The front side of the dike is vertical in this test series. The dike is made of laminated wood. To investigate the effect of the height of the strom wall, four different heights of storm wall were tested. The storm walls are with a height of $0 \mathrm{~m}, 0.6 \mathrm{~m}, 1.2 \mathrm{~m}$ and $1.8 \mathrm{~m}$ in prototype scale. The topography and the dike, consisting of a shallow foreshore and a steep dike, represent the configuration of the coastline at Wenduine, Belgium. 
For the measurement of the spatial wave height distribution, 12 resistance type wave gauges were used at six stations in the flume as shown in Figure 1. An array of three wave gauges was installed at St.1, St.2 and St.5 for analysis of incident and reflected waves. Each time series lasted approximately 40 minutes to obtain 1000 waves at a sampling frequency of $20 \mathrm{~Hz}$ in the model scale. In total four tests were conducted with this configuration with irregular waves (JONSWAP $\gamma=3.3$ ).
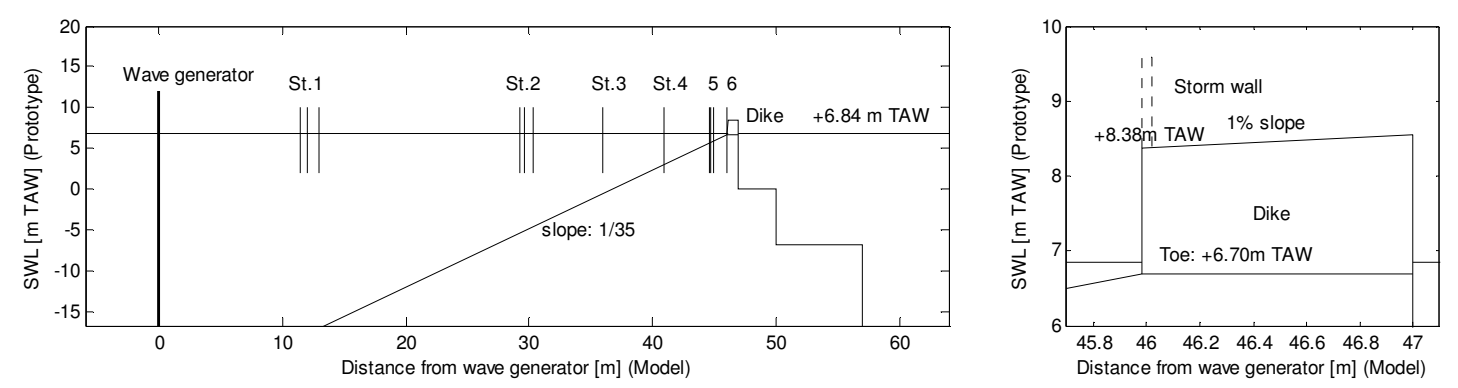

Figure 1. Experimental setup of wave transformation and wave overtopping on the Wenduine sea dike (SWL=6.84 m TAW, 1:25 scale)

\section{Numerical model set-up}

Numerical simulations were carried out with SWASH (version 1.05) using a grid size of $0.04 \mathrm{~m}$ in the horizontal direction with an initial time step of $0.005 \mathrm{~s}$ in model scale. One layer was used for the number of vertical layer since the $k d$ value ( $\mathrm{k}$ us the wavenumber) at the wave boundary in the model is smaller than 1.0, it is assumed that one layer resolves enough the frequency dispersion in case of $k d<$ 1.0. Note that the calculation time step is automatically adjusted in the calculation depends on the CFL condition. A maximum CFL value of 0.5 is used.

The physical model topography, as shown in Figure 1, was reproduced in the numerical domain. The storm walls are with a height of $0 \mathrm{~m}, 0.6 \mathrm{~m}, 1.2 \mathrm{~m}$ and $2.0 \mathrm{~m}$ in prototype scale in this simulation. The time series of the wave record at St. 1 at $12.0 \mathrm{~m}$ from the wave generator was prescribed as the wave boundary condition of the numerical simulation. Thus the length of the numerical flume was $52 \mathrm{~m}$ long with 1300 grid cells. A weakly-reflective boundary was applied at the wave boundary, and the Sommerfeld radiation condition was applied at the end of the numerical domain in order to minimize the effect of the reflection. A Manning's $\mathrm{n}$ value of 0.01 was used as a bottom friction in numerical model runs, as used in Suzuki et al. (2011) to represent the smooth material used in the physical model. The time duration of the numerical simulation was 40 minutes, the same as used in the physical model experiments.

\section{Comparison between SWASH and physical model}

Wave overtopping discharge was calculated directly using time varying layer thickness $h(t)$ and layer speed $u(t)$ at the end of the dike in the SWASH model. The mean overtopping discharge $q$ was calculated by the following equation.

$$
q=\int_{t s}^{t e} h(t) u(t) d t /(t e-t s)
$$

where $t s$ and $t e$ are start and end time of the wave overtopping measurement, respectively.

Figure 2 shows the comparison of wave overtopping discharge between the SWASH model and the physical model. As can be seen in the figure, the estimated wave overtopping by the SWASH model shows good agreement with the physical model. Hereafter all the results are shown in prototype scale.

\section{SENSITIVITY ANALYSIS}

Sensitivity analysis of the effect of beach nourishment on wave overtopping is conducted changing bottom configurations in the SWASH model. Three sets of bathymetries are used for sensitivity analysis, namely 1) beach levels, 2) beach slopes and 3) beach nourishment locations. The basic configuration of the model is the same as the validation case as shown in Figure 1; the beach slope is fixed at $1 / 35$, and the dike is vertical. 1000 year super storm condition is used as wave boundary 
condition; the water level is fixed at $+6.84 \mathrm{~m}$ TAW, significant incident wave height $\mathrm{H}_{\mathrm{m} 0}$ is $4.75 \mathrm{~m}$, peak period $\mathrm{T}_{\mathrm{p}}$ is $11.75 \mathrm{~s}$ at wave gauge station St.2 (refer to Figure 1). The beach profiles represent the beach at the maximum water level, taking account the erosion during the storm.

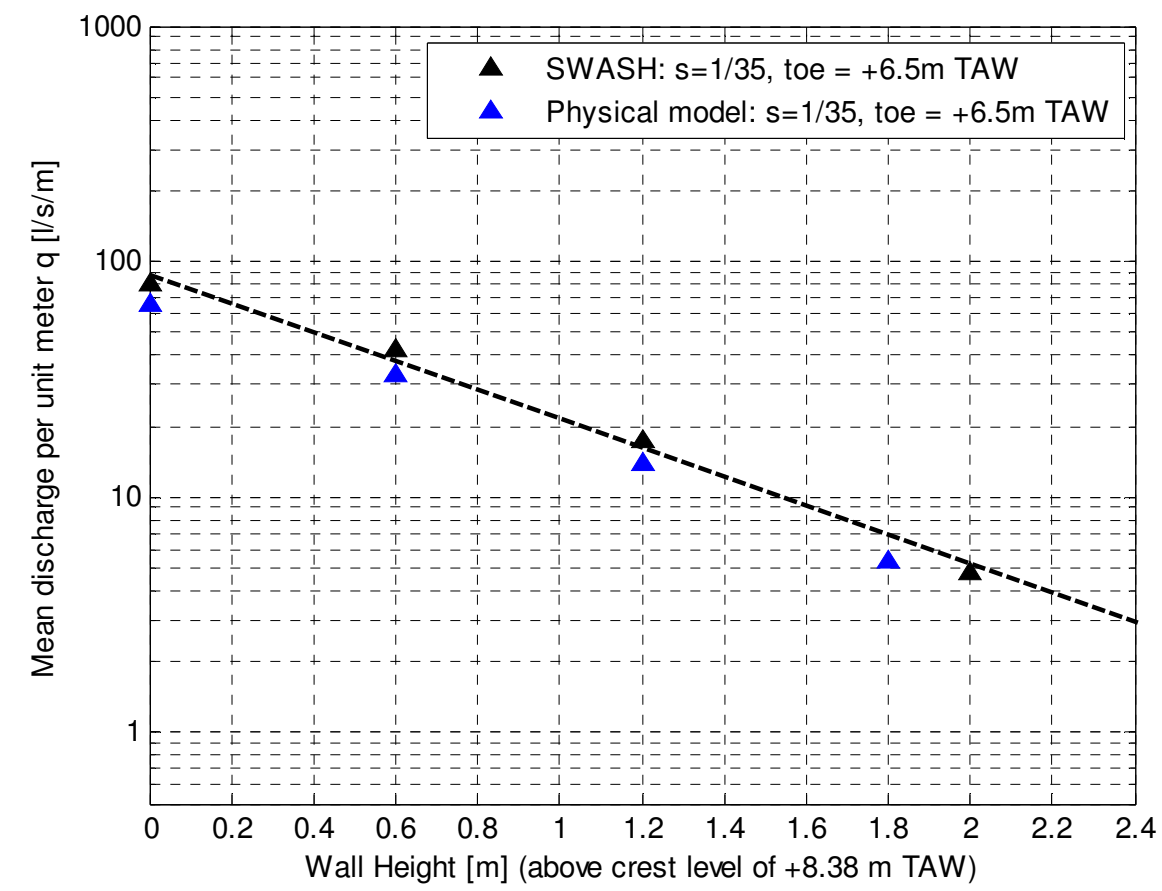

Figure 2. Numerical model and physical model for mean wave overtopping discharge against different storm wall height.

\section{Beach levels}

The effect of the beach level is investigated by shifting the toe level from $+5.0 \mathrm{~m}$ TAW to $+7.5 \mathrm{~m}$ TAW with the fixed slope $1 / 35$. The still water level is $+6.84 \mathrm{~m}$ TAW. Two configurations of the wall conditions are tested, namely without wall and with $1.2 \mathrm{~m}$ wall. Figure 3 shows the configurations of this model.

Figure 4 shows the relationship between toe level and wave overtopping discharge calculated by the SWASH model. As can be seen in the figure, the estimated wave overtopping discharge in SWASH model shows logarithmic reduction with increasing beach level up to still water level. The reduction rate becomes slightly smaller when the toe level exceeds still water level.
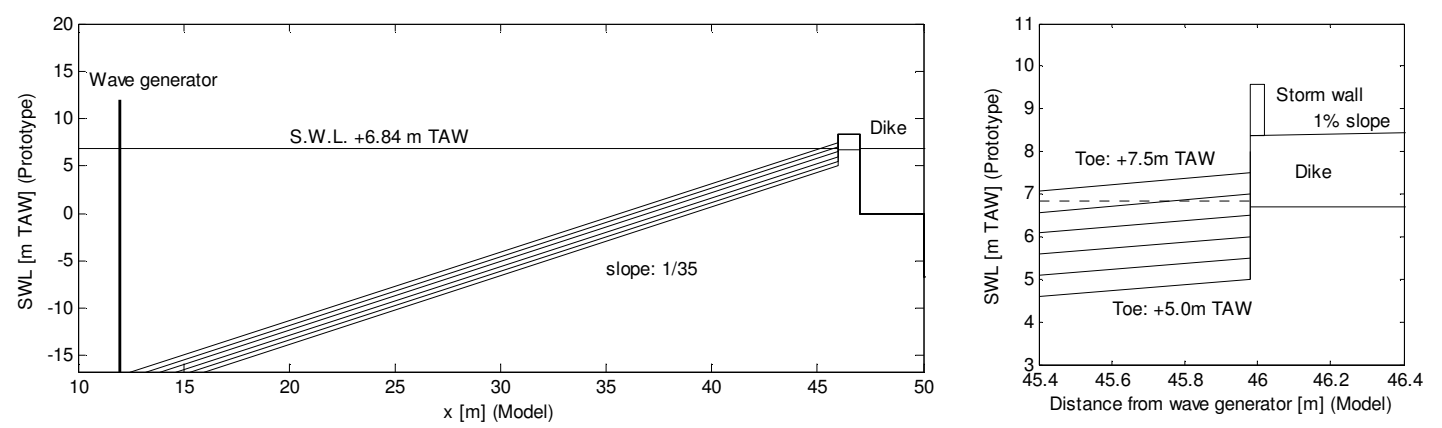

Figure 3. Numerical experiment setup for different beach levels. Left shows the entire figure and right is a close up of at the dike. 


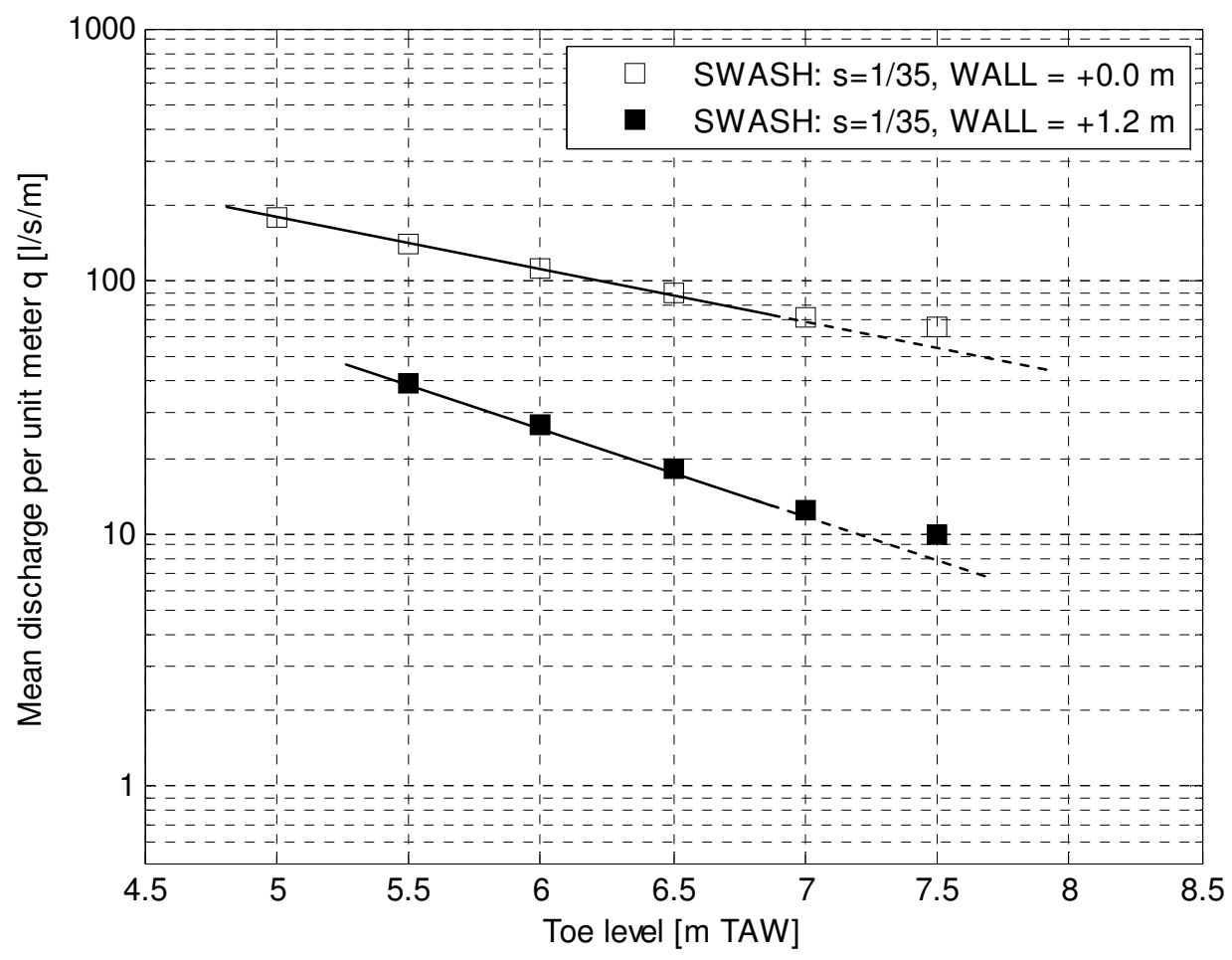

Figure 4. Numerical results for mean wave overtopping discharge as a function of beach level.

To elaborate on the mechanism of how the bottom level affects wave overtopping, the wave transformation for the selected test cases was investigated further. In this study, the toe level $+5.5 \mathrm{~m}$ and $+7.0 \mathrm{~m}$ TAW with $1.2 \mathrm{~m}$ wall condition were selected. It is noted that the S.W.L. is $+6.84 \mathrm{~m} \mathrm{TAW}$. The mean overtopping discharges per unit meter are 39 and $12 \mathrm{l} / \mathrm{s} / \mathrm{m}$, respectively for the $+5.5 \mathrm{~m}$ TAW and $+7.0 \mathrm{~m}$ TAW toe level.

Figure 5 compares the significant wave height from spectral analysis $\left(H_{m 0}=4 \sqrt{ } m_{0}\right)$ and wave setup for each case. Here the parameters are based on the entire wave spectra, thus including both incident and reflected waves. As can be seen in Figure 5, the significant wave height from the toe level of +5.5 $\mathrm{m}$ exceeds the one from $+7.0 \mathrm{~m}$ behind St.3. The wave breaking started between St. 2 - St.4 for both cases, therefore, it is clear that the difference of the wave height between them are due to wave breaking induced by the different depths. On the other hand, wave set-up shows the opposite trend that $+7.0 \mathrm{~m}$ case exceeds the $+5.5 \mathrm{~m}$ case. This also can be explained by the difference of the bottom level. The shallower the depth, the more wave set-up can be observed.

Figure 6 shows the wave energy spectrum at each station. For each case, the wave energy spectrum shifts from high frequencies to low frequencies. This is a typical wave transformation pattern on the shallow foreshore due to infragravity wave formation. Even though toe levels are different, the peak wave period does not change so much. Only differences are magnitude of the power spectrum.

Figure 7 shows a part of the time series of free-surface elevation at each station. The discrepancies become noticeable as the wave propagates towards the dike. At St.5 and St.6, wave period becomes much higher compared to the wave period in the offshore wave gauges as can be seen in the spectral analysis in Figure 6. At St.6, the free surface elevation for the case of $+7.0 \mathrm{~m}$ can only be seen above zero level since bottom level is higher by $0.14 \mathrm{~m}$ from S.W.L.

Figure 8 shows full time series of the layer thickness $h(\mathrm{t})$ and layer speed $u(\mathrm{t})$ at the end of the dike, instantaneous wave overtopping discharge $q(\mathrm{t})$ estimated by Eq. (6), and free-surface elevation at the toe of the dike (St.6). The dotted line in the figure of the free-surface elevation shows the crest level of the storm wall. As can be seen in the figure, the number of the overtopping event in $+5.5 \mathrm{~m}$ case is much higher than one in $+7.0 \mathrm{~m}$ case.

From these analyses, it can be concluded that the higher beach level causes more wave dissipation due to wave breaking, and thus wave overtopping discharge is also lower. 

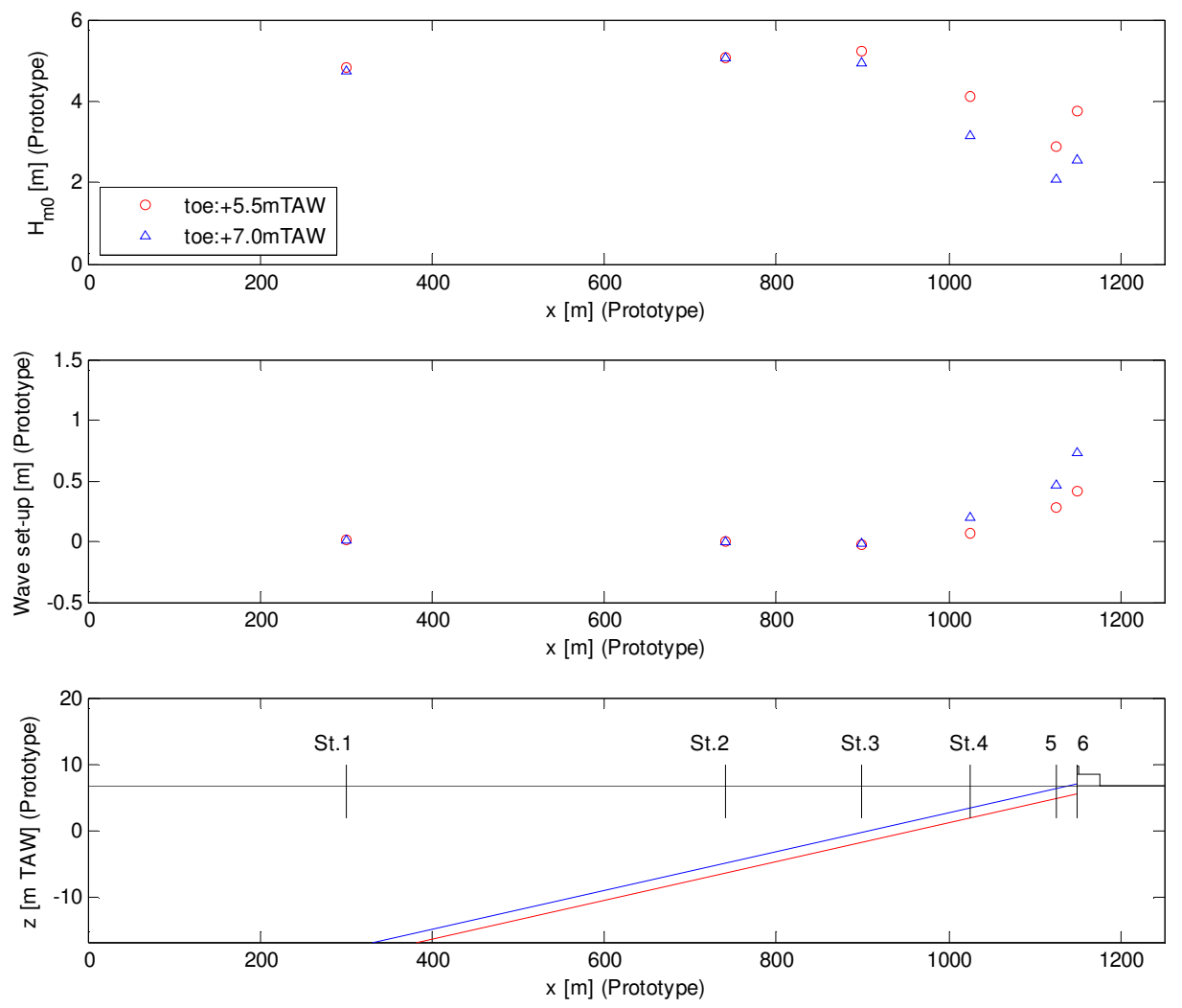

Figure 5. Comparison between the toe level of $+5.5 \mathrm{~m}$ and $+7.0 \mathrm{~m}$ TAW for the spatial distribution of $\mathrm{Hm} 0$ and wave set-up.

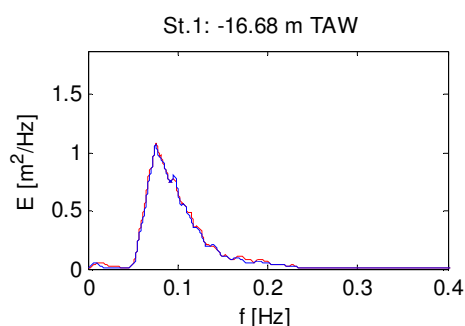

St.4: 25 . Hs from toe

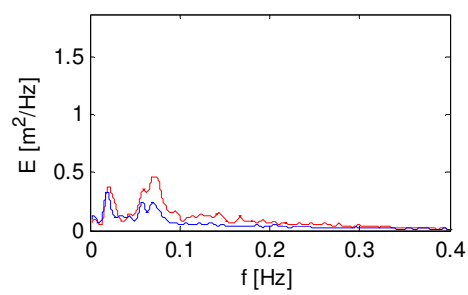

St.2: -5.0 m TAW

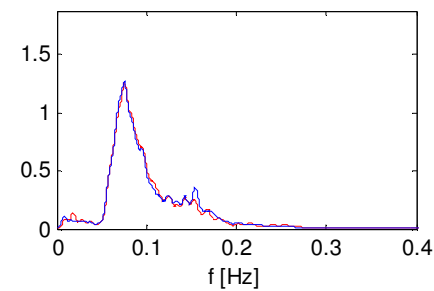

St.5: 5. Hs from toe

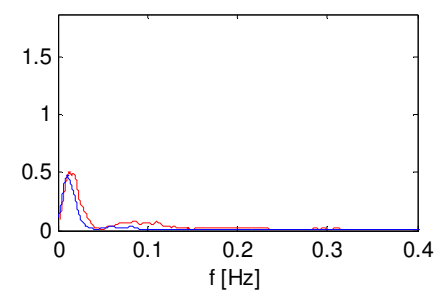

St.3: 50. Hs from toe

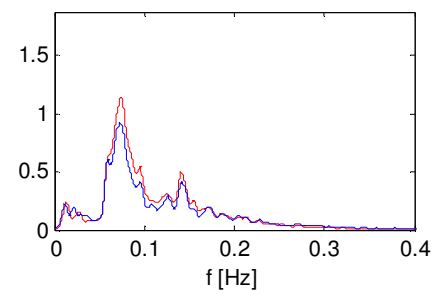

St.6: Toe of dike

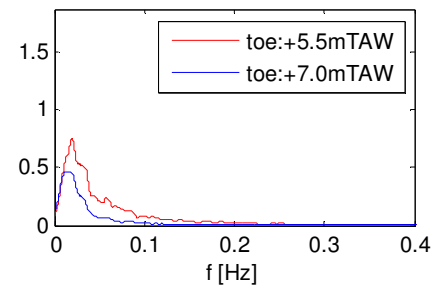

Figure 6. Comparison between the toe level of $+5.5 \mathrm{~m}$ and $+7.0 \mathrm{~m}$ TAW for the wave energy spectrum at each station. 

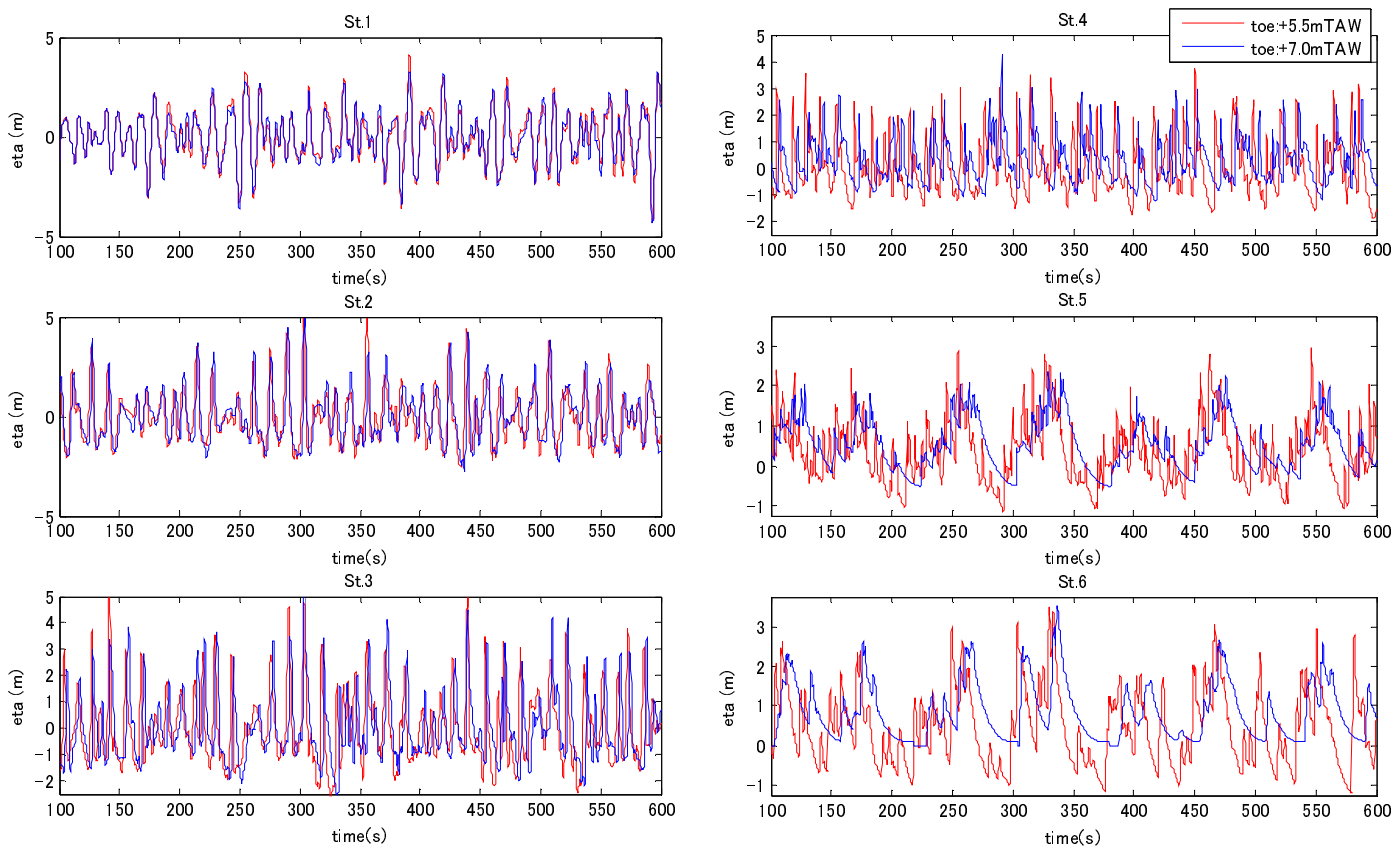

Figure 7. Comparison between the toe level of $+5.5 \mathrm{~m}$ and $+7.0 \mathrm{~m}$ TAW for the time series of free-surface elevation at each station.
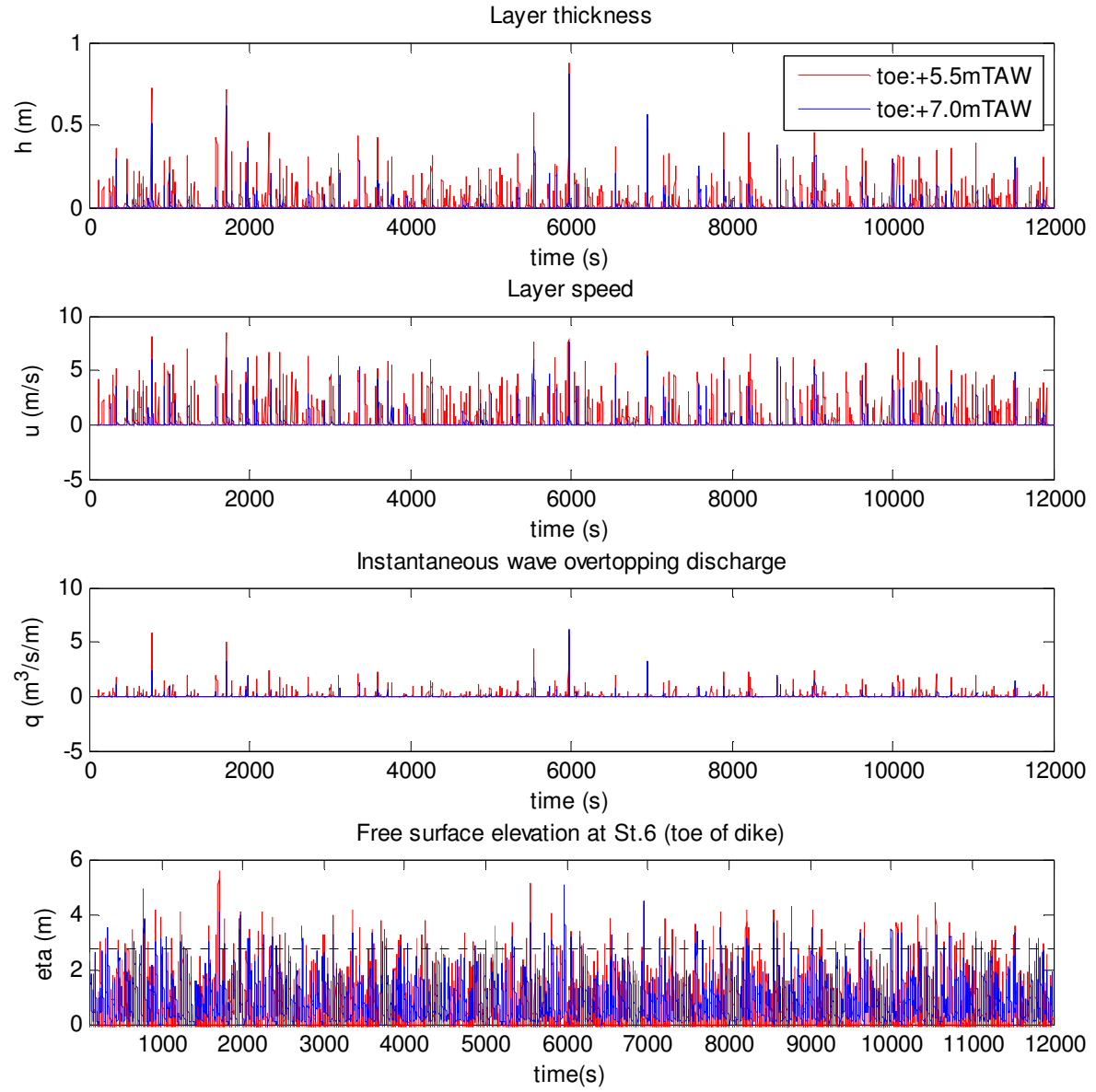

Figure 8. Comparison between the toe level of $+5.5 \mathrm{~m}$ and $+7.0 \mathrm{~m}$ TAW for the time series of layer speed, velocity, discharge and free surface elevation. 


\section{Beach slopes}

Beach nourishment is not always distributed equally in space such as the beach level sensitivity analysis in the last section, especially at the first stage of beach nourishment. Certainly the eroded profile can show different behavior (e.g. rather flat beach or with steep cliffs). Thus, to obtain knowledge about the effect of beach slope against wave overtopping discharge is also useful information for the beach nourishment design strategies.

The effect of the beach slope on wave overtopping discharge is investigated by changing the slope from $1 / 5$ to $1 / 30$ on the fixed slope of $1 / 35$ with the toe level of $+6.5 \mathrm{~m}$ TAW. A $1.2 \mathrm{~m}$ wall is allocated on the sea dike. These slopes start from the crest level of the dike at $+8.38 \mathrm{~m}$ TAW. These might not be typical configurations of beach nourishment (after erosion), however, qualitative assessment on beach slope effect can be delivered from this sensitivity analysis. Figure 9 shows the configurations of this test. The left figure shows the entire domain and right figure show the area nearby the vertical dike. As can be seen in the figure, the total amount of the sand to achieve each slope varies a lot; the 1/30 slope needs the largest sand volume in these configurations.
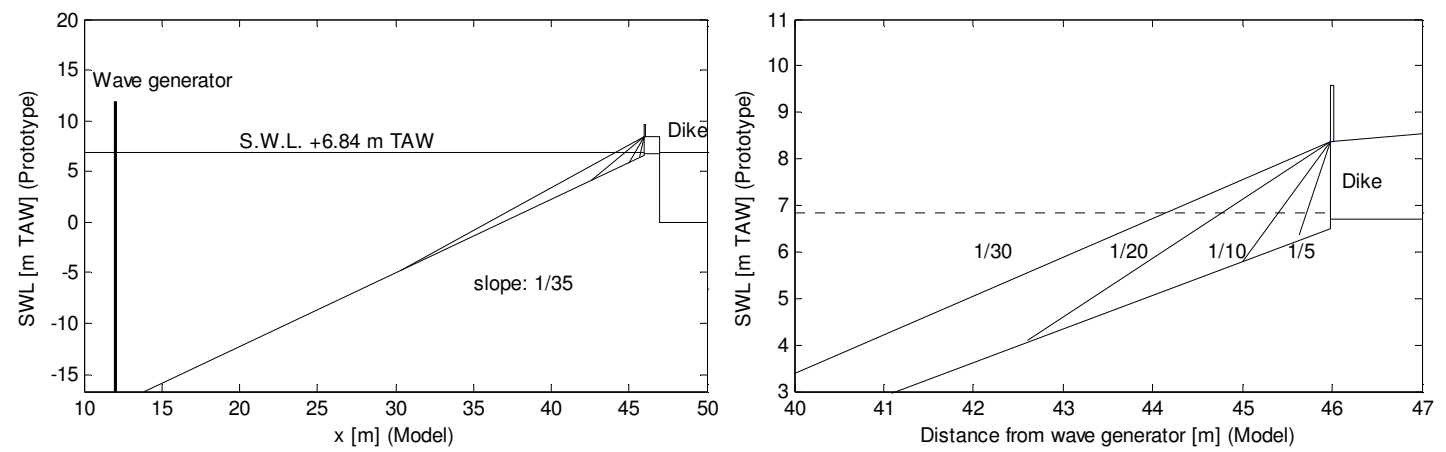

Figure 9. Configuration of beach slopes for $1 / 5,1 / 10,1 / 20$ and 1/30. Left shows the entire domain and right shows near the dike. Toe level, dike crest and wall crest level are $+6.50 \mathrm{~m}$ TAW,$+8.38 \mathrm{~m}$ TAW and $+9.58 \mathrm{~m}$ TAW, respectively.

Figure 10 shows the relationship the between beach slope 1/x and the mean wave overtopping discharge calculated by the SWASH model. As can be seen in the figure, the estimated wave overtopping discharge shows a parabolic curve against the beach slope. It shows that the maximum overtopping is in between $1 / 10$ and $1 / 20$ beach slope. It is interesting that the total amount of the sand volume is relatively large in the case of $1 / 10$ and $1 / 20$, wave overtopping discharge is increased compared to no beach nourishment. Wave overtopping is only reduced when the slope reached to $1 / 30$. From this, it can be concluded that the beach nourishment should be such that cliff erosion is avoided.

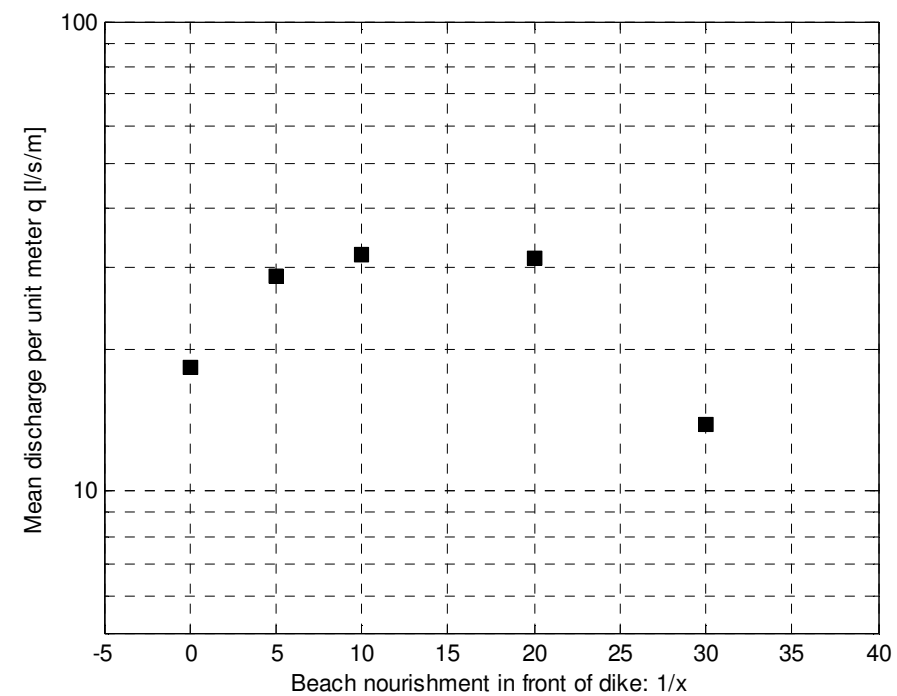

Figure 10. Numerical model and physical model for mean wave overtopping discharge against different beach slope. 
To clarify the effect of the beach slope for overtopping, the detailed wave analysis for the selected test cases were conducted. In this study, the slope of $1 / 10$ and no slope condition were selected. The mean overtopping discharges per unit meter are 32 and $18 \mathrm{l} / \mathrm{s} / \mathrm{m}$ for these respective test cases.

Figure 11 compares the significant wave height and wave set-up for each case. The significant wave height from 1/10 slope exceeds the one at no slope at St.5. On the contrary, the significant wave height from no slope exceeds the one from 1/10 slope at St.6. In general, wave overtopping becomes large when wave height at the toe of dike is high. However, the overtopping result shows the opposite. This would be explained by the fact that the wave set-up is very high at 1/10 slope condition. Figure 12 shows the wave energy spectrum at each station. Figure 13 and Figure 14 show the time series of each wave gauge and instantaneous overtopping discharge.
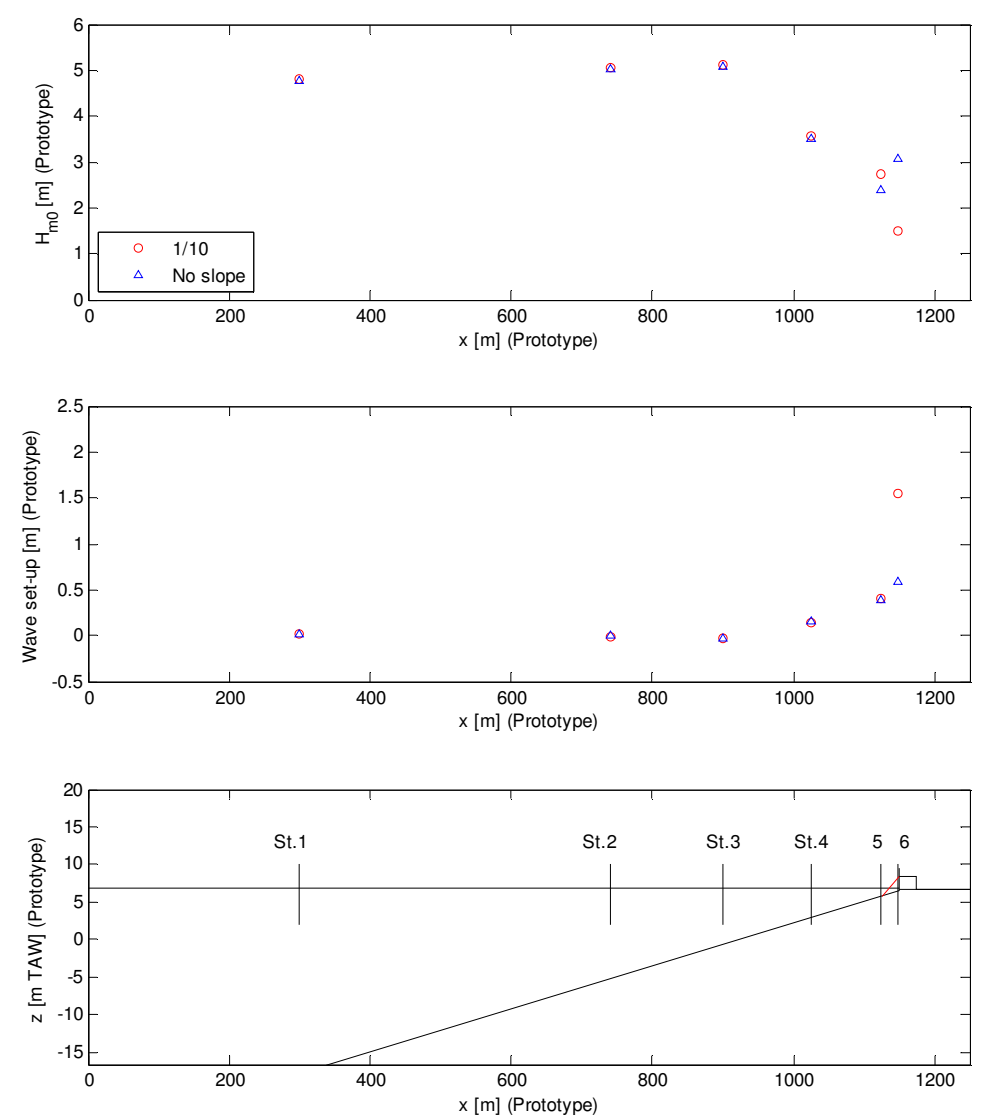

Figure 11. Comparison between 1/10 slope and no slope for the spatial distribution of $\mathrm{H}_{\mathrm{m} 0}$ and wave set-up.
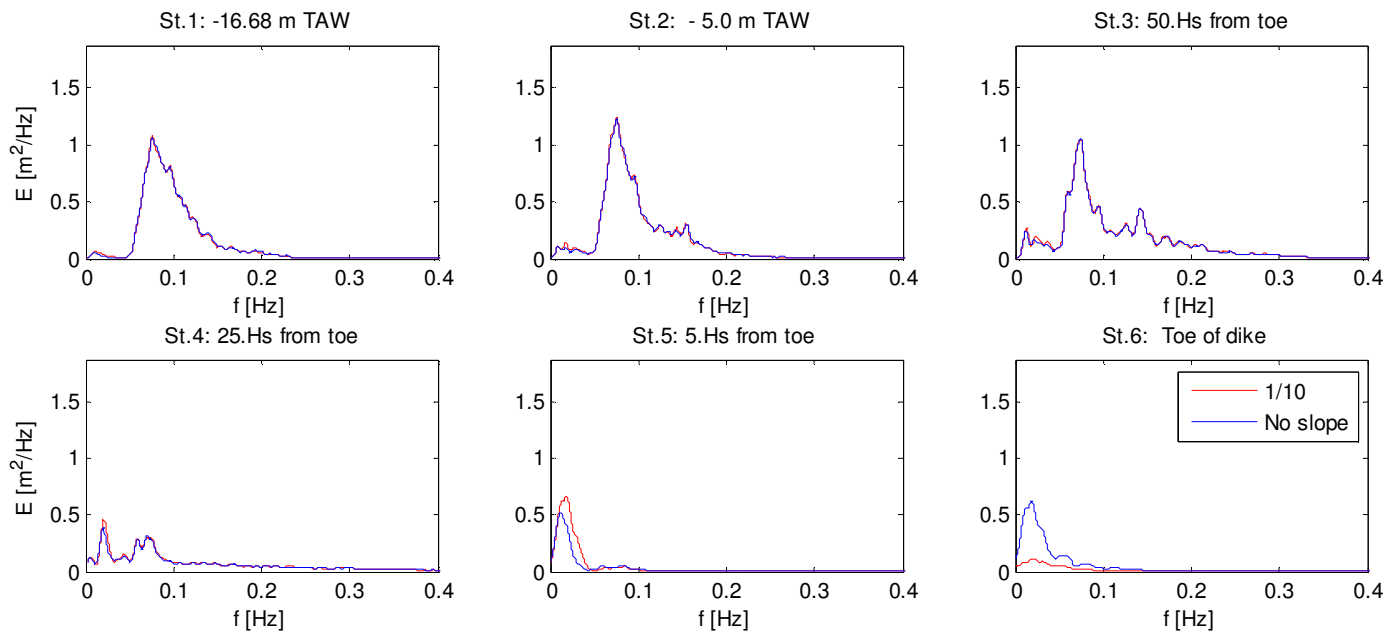

Figure 12. Comparison between $1 / 10$ slope and no slope for the wave energy spectrum at each station. 

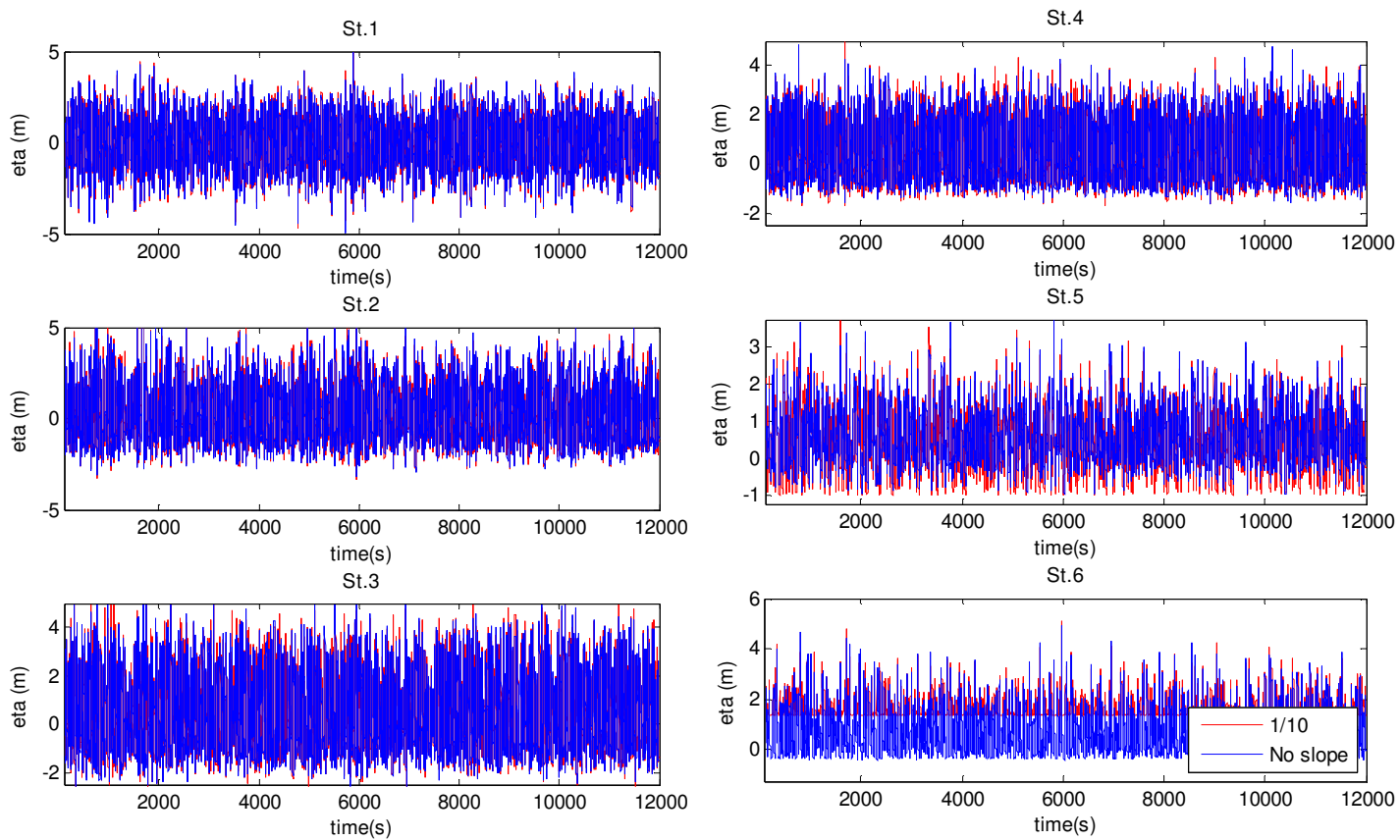

Figure 13. Comparison between $1 / 10$ slope and no slope for the time series of free-surface elevation at each station.
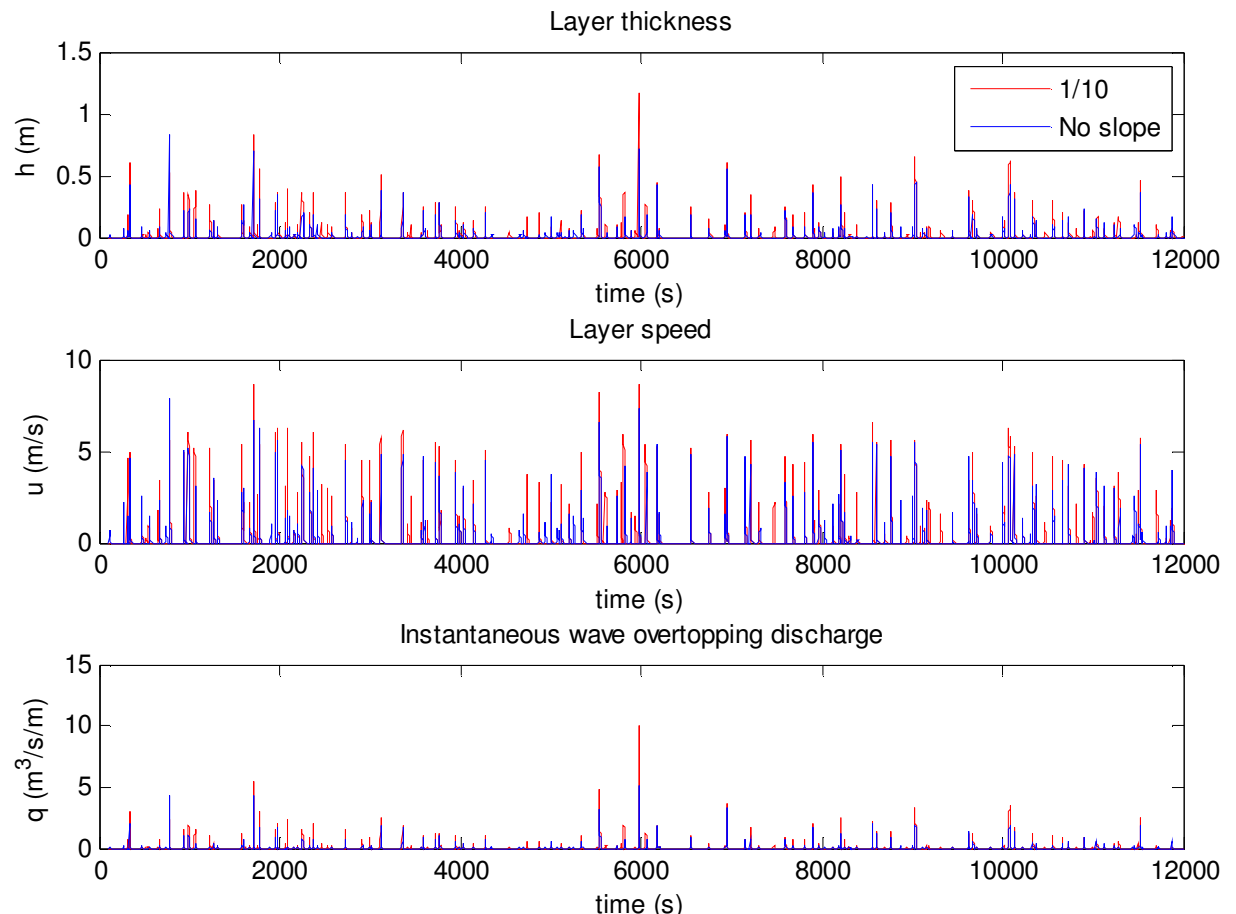

Free surface elevation at St. 6 (toe of dike)

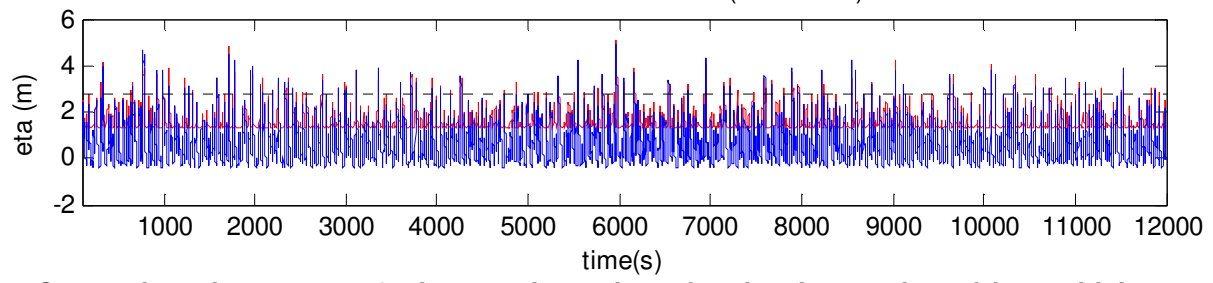

Figure 14. Comparison between 1/10 slope and no slope for the time series of layer thickness, velocity, discharge and free-surface elevation. 
Even though the wave heights at the toe of the dike for the 1/10 slope is small, overtopping discharge is almost two times larger than no slope case. To understand this phenomenon, visual observations in the flume are useful. Figure 15 shows one example of a snap shot of the wave tip in front of the dike for physical model and SWASH model.

As can be seen in the figure, the wave tip becames a bore-like wave. This typically can be seen in shallow foreshores. During wave transformation from deep water to shallow water, most of the energy is transferred from high frequency to low frequency due to wave breaking. Occasionally big bores are generated from 4-5 waves by wave grouping effect in the surf zone. This phenomenon is described as an infragravity wave (e.g. Schaffer 1993; Baldock et al. 1997).

Since the bottom level near the dike is almost same level as still water level, bores rather than waves are dominant in this region. The reason that $1 / 10$ slope case has more overtopping than no slope case can be explained by the characteristics of the bores. If there is no slope, the bore impact is almost perpendicular to the vertical storm wall and dike. Then the horizontal momentum is converted into vertical momentum. This would be the reason why the wave crests are higher with the no slope condition as can be seen in the Figure 13 and 14. On the other hand, horizontal momentum is not reduced as much in the case of 1/10 slope due to the effect of the slope in front of the vertical storm wall. It should be noted that this effect can be dominant only when the dike is vertical or very steep.
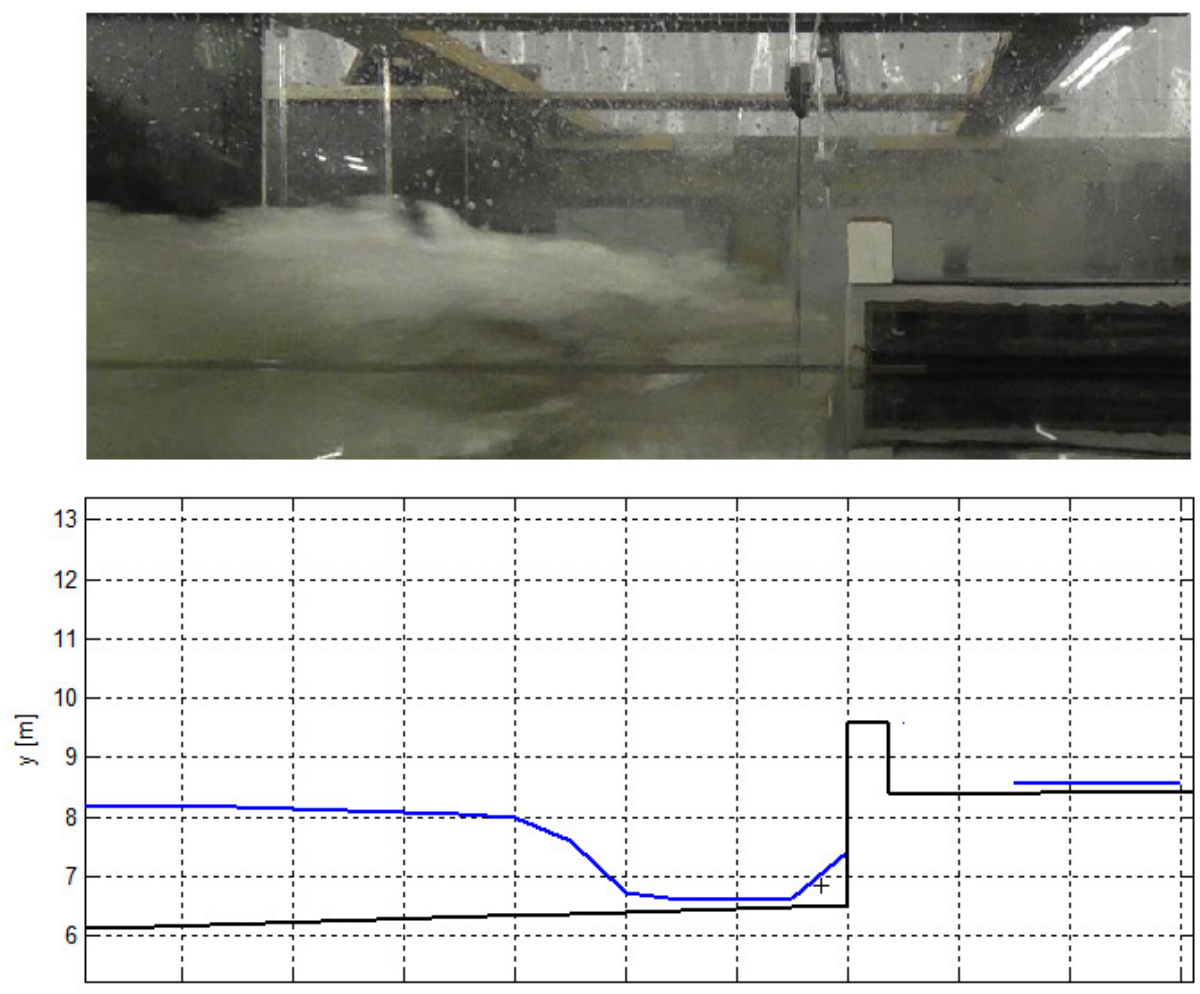

Figure 15. One example of snap shot of wave tip in front of the dike from physical model and SWASH model.

\section{Beach nourishment locations}

The location of beach nourishment / shape of the eroded profile can also influence wave overtopping discharge. The effect of the beach nourishment location on overtopping discharge is investigated by changing the beach nourishment position from the sea dike side to further offshore. The amount of the sand is fixed as $80 \mathrm{~m}^{3} / \mathrm{m}$. The crest levels are also changed from $+7.0 \mathrm{~m}$ to $+5.0 \mathrm{~m}$ TAW depending on the positions. The sea ward slope of the nourishment is also fixed in $1 / 10$. A $1.2 \mathrm{~m}$ wall is allocated on the sea dike to compare the condition with other sensitivity analyses.

Figure 16 shows the configurations of this test. The left figure shows the entire domain and the right figure shows the area close to the vertical dike. 

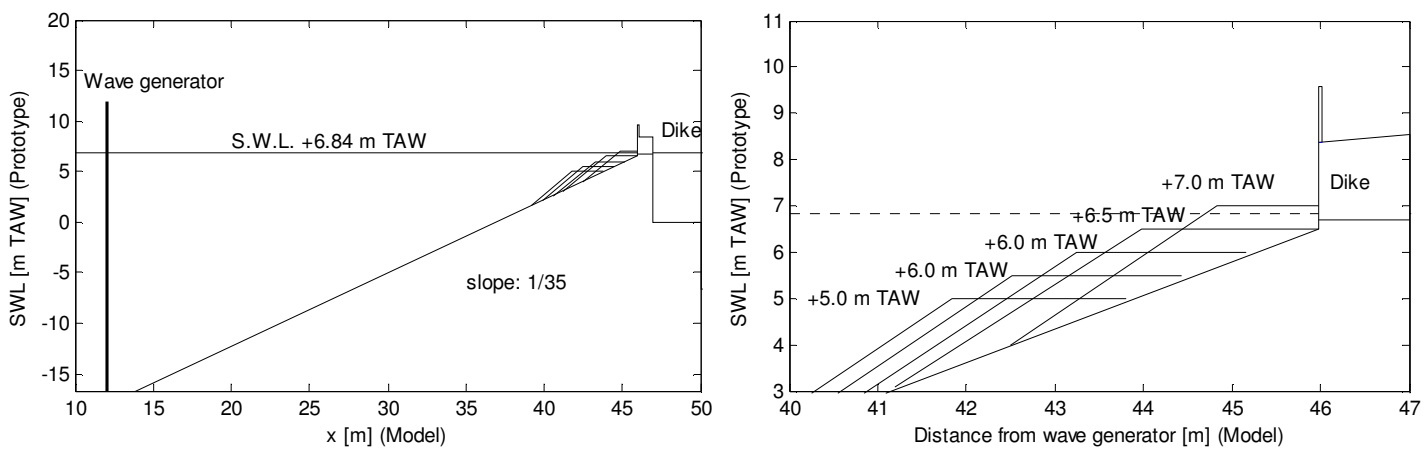

Figure 16. Numerical experiment setup for different beach nourishment positions. Left shows the entire figure and right shows near the dike.

Figure 17 shows the relationship the between crest level of beach nourishment (beach nourishment position) and the mean wave overtopping discharge calculated by the SWASH model. As can be seen in the figure, the estimated wave overtopping discharge shows weak trend against the beach nourishment position. It shows that the minimum overtopping is around the crest level of $+6.0 \mathrm{~m}$ TAW. It is noted that the S.W.L. is $+6.84 \mathrm{~m}$ TAW. From this result, the position also influences the overtopping. However, it seems that the difference is relatively small compared to the bottom level and slope effect investigated earlier.

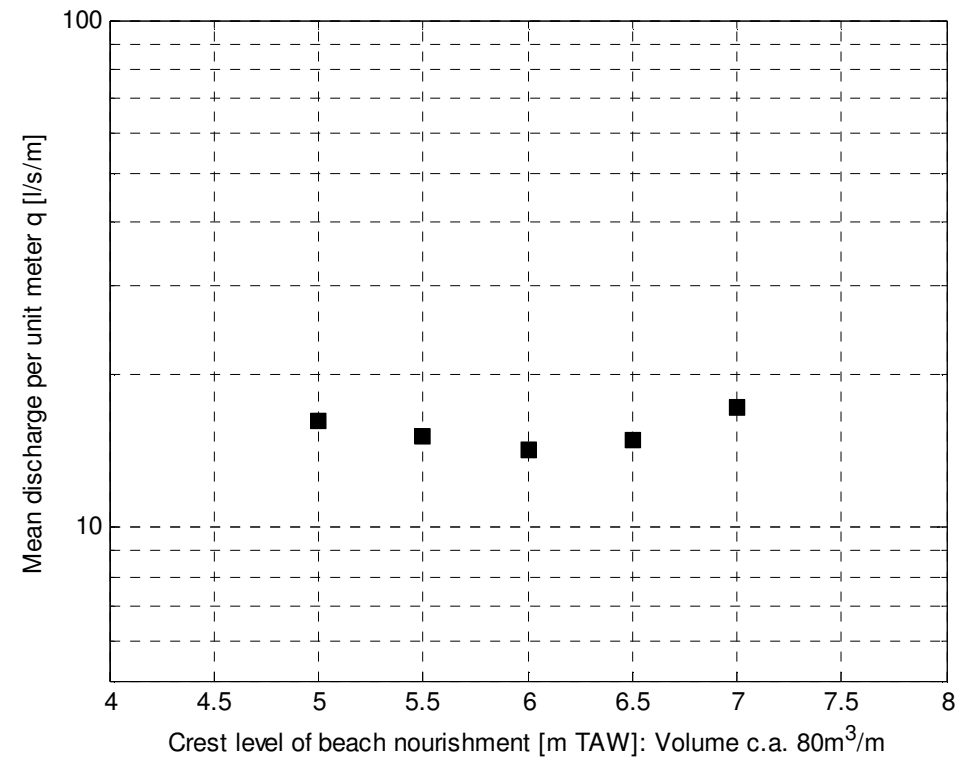

Figure 17. Numerical model and physical model for mean wave overtopping discharge against different beach nourishment positions.

\section{CONCLUSIONS}

The SWASH numerical model has been applied to study the effect of beach nourishment on wave overtopping in shallow foreshores. The key conclusions from this study are summarized as follows.

- Good agreement with physical mean wave overtopping results are obtained with the SWASH model.

- Low frequency infragravity waves (bores) are generated on the shallow foreshore.

- Beach nourishment does not always gives positive effects for reduction of wave overtopping discharge of vertical dikes on shallow foreshores.

- To reduce wave overtopping discharge in a shallow foreshore, the horizontal momentum of the bores have to be reduced. 
From the sensitivity analysis, it becomes clear that wave overtopping discharge on shallow foreshores is characterized by bores generated in surf zone due to wave breaking. To reduce wave overtopping discharge in shallow foreshore, it is important to reduce horizontal momentum of the bores.

In addition, this study does not consider the effects of directional wave spreading. Investigation into the effect provides ground for future work.

\section{REFERENCES}

Afdeling Kust (2011). Coastal Safety Masterplan [Masterplan Kustveiligheid] [Online]. Available: http://www.kustveiligheid.be/

Baldock, T.E., Holmes, P., Horn, D.P., (1997) Low frequency swash motion induced by wave grouping. Coastal Engineering 32, 197-222.

EurOtop. (2007) Wave Overtopping of Sea Defences and Related Structures: Assessment Manual, Environment Agency UK/Expertise Netwerk Waterkeren NL/Kuratorium fur Forschung im Kusteningenieurswesen DE. 2007.

Lara, J. L., Losada, I. J., \& Guanche, R. (2008). Wave interaction with low-mound breakwaters using a RANS model. Ocean Engineering 35, 1388-1400.

Schaffer, H.A. (1993) Infragravity waves forced by short wave groups. Journal of Fluid Mechanics 247, 551-588.

Suzuki, T., Verwaest, T., Hassan, W., Veale, W., Reyns, J., Trouw, K., Troch, P. and Zijlema, M. (2011) The applicability of SWASH for modelling wave transformation and wave overtopping: A case study for the Flemish coast. Proceedings in ACOMEN 2011.

Troch, P., De Rouck, J. and Schuttrumpf, H. (2002) Numerical simulation of wave overtopping over a smooth impermeable sea dike. Advances in Fluid Mechanics IV, 715-724.

Van Gent, M. R. A. (1999). Physical model investigations on coastal structures with shallow foreshore: 2D model tests with single and doube-peaked wave energy spectra. WL I Delft Hydrauilcs.

Van Gent, M.R.A. (2001) Wave runup on dikes with shallow foreshores. Journal of Waterway, Port, Coastal, and Ocean Engineering, 127(5): 254-262.

Van Gent, M.R.A. and Giarrusso, C.C. (2003) Influence of low-frequency waves on wave overtopping; A study based on field measurements at the Petten Sea-defence. WL I Delft Hydrauilcs.

Veale, W., Suzuki, T., Spiesschaert, T.,Verwaest, T. and Mostaert, F. (2011). SUSCOD Pilot 1: Wenduine Wave Overtopping Scale Model: Interim Results Report. Version 2_0. WL Rapporten, WL2011R75902a_1rev2_0. Flanders Hydraulics Research.

Verwaest, T.; Van der Biest, K.; Vanpoucke, Ph.; Reyns, J.; Vanderkimpen, P.; De Vos, L.; De Rouck, J.; Mertens, T. (2009). Coastal flooding risk calculations for the Belgian coast, in: McKee Smith, J. (Ed.) Proceedings of the 31st International Conference on Coastal Engineering 2008, Hamburg, Germany, 31 August to 5 September 2008. pp. 4193-4201

Zijlema, M., Stelling, G.S. and Smit P. (2011) SWASH: An operational public domain code for simulating wave fields and rapidly varied flows in coastal waters. Coastal Engineering, 58: 9921012. 